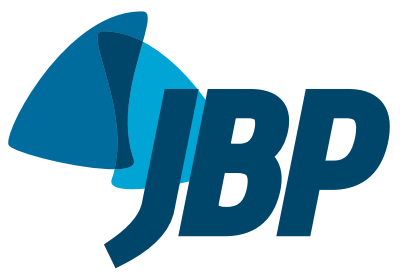

\title{
Lack of association between viral load and severity of acute bronchiolitis in infants
}

\author{
Ana Paula Duarte de Souza'1, Lidiane Alves de Azeredo Leitão², \\ Fernanda Luisi ${ }^{2}$, Rodrigo Godinho Souza ${ }^{2}$, Sandra Eugênia Coutinho ${ }^{2}$, \\ Jaqueline Ramos da Silva², Rita Mattiello², Paulo Márcio Condessa Pitrez ${ }^{2}$, \\ Renato Tetelbom Stein ${ }^{2}$, Leonardo Araújo Pinto ${ }^{2}$
}

1. Laboratório de Imunologia Clínica e Experimental, Instituto de Pesquisas Biomédicas, Centro Infant, Pontifícia Universidade Católica do Rio Grande do Sul - PUCRS - Porto Alegre (RS) Brasil.

2 Laboratório de Respirologia Pediátrica, Instituto de Pesquisas Biomédicas, Infant Center, Pontifícia Universidade Católica do Rio Grande do Sul - PUCRS - Porto Alegre (RS) Brasil.

Submitted: 22 September 2015. Accepted: 25 February 2016

Study carried out at the Centro Infant, Instituto de Pesquisas Biomédicas, Pontifícia Universidade Católica do Rio Grande do Sul - PUCRS - Porto Alegre (RS) Brasil.

\begin{abstract}
Objective: To investigate the correlation between respiratory syncytial viral load and length of hospitalization in infants with acute wheezing episodes. Methods: This was a two-year, cross-sectional study of infants $\leq 12$ months of age with bronchiolitis at the time of admission to a tertiary hospital. For the identification of respiratory viruses, nasopharyngeal secretions were collected. Samples were analyzed (throughout the study period) by direct immunofluorescence and (in the second year of the study) by quantitative real-time $P C R$. We screened for three human viruses: rhinovirus, respiratory syncytial virus, and metapneumovirus. Results: Of 110 samples evaluated by direct immunofluorescence, 56 (50.9\%) were positive for a single virus, and 16 (14.5\%) were positive for two or more viruses. Among those 72 samples, the most prevalent virus was respiratory syncytial virus, followed by influenza. Of 56 samples evaluated by quantitative real-time PCR, 24 (42.8\%) were positive for a single virus, and 1 (1.7\%) was positive for two viruses. Among those 25 samples, the most prevalent virus was again respiratory syncytial virus, followed by human rhinovirus. Coinfection did not influence the length of the hospital stay or other outcome s. In addition, there was no association between respiratory syncytial virus load and the length of hospitalization. Conclusions: Neither coinfection nor respiratory syncytial viral load appears to influence the outcomes of acute bronchiolitis in infants.
\end{abstract}

Keywords: Bronchiolitis; Coinfection; Viral load; Hospitalization; Respiratory syncytial virus, human.

\section{INTRODUCTION}

Respiratory distress and wheezing are very common respiratory symptoms in children and may be the clinical expression of a wide variety of problems in the respiratory tract. Regardless of the cause, wheezing is a frequent reason for seeking medical care in the emergency room, especially during the first years of life. ${ }^{(1)}$ The main cause of wheezing in infants is acute viral bronchiolitis, which is often accompanied by other risk factors, such as maternal smoking and premature birth.

One study reported that almost half of a population under one year of age seen in an emergency department presented with respiratory symptoms. ${ }^{(2)}$ In another study, it was reported that $17 \%$ of children with wheezing had been hospitalized at least once during the first year of life. (3) The leading cause of hospitalization among those infants was acute bronchiolitis caused by infection with viruses of the family Paramyxoviridae, which includes the human respiratory syncytial virus (RSV), of the genus Pneumovirus. Other agents that have been often linked to bronchiolitis and recurrent wheezing: viruses of the family Adenoviridae, including the various human adenoviruses within the genus Mastadenovirus; viruses of the family Picornaviridae, such as those of the genus Enterovirus, which comprises several human rhinoviruses (HRVs), including the species Human rhinovirus $A, B$, and $C$; other viruses of the Paramyxoviridae family, especially the various Human parainfluenza virus species of the Respirovirus genus and the Human metapneumovirus (HMPV) species of the genus Metapneumovirus; and viruses of the family Orthomyxoviridae, which includes the genera Influenza virus $A, B$, and $C$. The rate of coinfection is also high. In one study, RSV occurred as a single infection in $68.8 \%$ of children with wheezing, whereas nearly a third were coinfected with another respiratory virus. ${ }^{(4)}$ The viruses most frequently associated with RSV are HMPV and HRVs. ${ }^{(5)}$ Such infections result in high costs to the health system, as well as impairing the quality of life of the infants and the family. One major question that is still open to debate is the role that the viral load, especially that of RSV, plays in determining the severity of acute wheezing episodes. ${ }^{(6)}$ In the present study, we evaluated the occurrence of infection and coinfection with respiratory viruses in infants with wheezing at the time of hospital admission, as well as the association between viral load and outcomes related to disease severity.

\section{Correspondence to:}

Leonardo A. Pinto, Instituto de Pesquisas Biomédicas, Hospital São Lucas da PUCRS, Avenida Ipiranga, 6690, $2^{\circ}$ andar, Instituto de Pesquisas Biomédicas, CEP 90.610 000 , Porto Alegre, RS, Brasil.

Tel.: 5551 3320-2313. Fax: 5551 3320-3312. E-mail: leonardo.pinto@pucrs.br

Financial support: This study received financial support from the Fundação de Amparo à Pesquisa do Estado do Rio Grande do Su/(FAPERGS, Foundation for the Support of Research in the State of Rio Grande do Sul) and the Brazilian Coordenação de Aperfeiçoamento de Pessoal de Nive/ Superior (CAPES, Office for the Advancement of Higher Education). 


\section{METHODS}

This was a cross-sectional study of infants up to 12 months of age with acute bronchiolitis who were admitted to a tertiary hospital—Hospital São Lucas, operated by the Pontifical Catholic University of Rio Grande do Sul-in the city of Porto Alegre, Brazil, between September of 2009 and August of 2011. The inclusion criteria were being $\leq 12$ months of age; having been admitted with a clinical diagnosis of acute bronchiolitis (based on prodromal symptoms, with wheezing, crackles, and tachypnea); having been recruited within the first $48 \mathrm{~h}$ of hospitalization; and having a $\leq 72-\mathrm{h}$ history of clinical manifestations of lower respiratory tract infection (wheeze or respiratory distress). Patients with a history of lung disease related to prematurity (such as bronchopulmonary dysplasia) were excluded, as were those with congenital heart disease, chronic lung disease (cystic fibrosis or bronchiolitis obliterans), or clinical symptoms suggestive of Bordetella pertussis infection, as well as those who had used macrolides previously.

Data regarding clinical conditions at the time of hospital admission, vital signs, and signs of respiratory distress were obtained from medical charts. Medical histories were collected from parents or guardians with a standardized questionnaire. Information regarding the clinical course of the disease until discharge, such as the length of hospital stay, duration of oxygen therapy, and wheezing, was collected by the study physicians and researchers, as was information related to demographic variables at admission.

On the first day of hospitalization, all patients underwent nasopharyngeal lavage for the identification of respiratory viruses. To avoid the inclusion of infants in the convalescence period, we recruited and collected samples only from patients who had a $\leq 72$-h history of clinical manifestations of lower respiratory tract infection (wheeze or respiratory distress). Sample collection and immunofluorescence are routine in the assessment of infants with bronchiolitis at Hospital São Lucas., although PCR is not. All samples collected during the second year of the study were frozen at $-80^{\circ} \mathrm{C}$ and stored for subsequent PCR testing.

Direct immunofluorescence (DIF) for RSV, adenovirus, parainfluenza, and influenza was performed for the detection of antigens in nasopharyngeal secretions. For DIF, a specific antibody labeled with fluorochrome conjugate (Biotrin, Dublin, Ireland) was used for the monoclonal antibody group-specific and type-specific detections and culture confirmation. This test was performed in all patients evaluated during the study period (September of 2009 to August of 2011) and was used in order to investigate the role that the number of different viruses plays in determining the severity of acute bronchiolitis. We defined two groups of patients: those infected with a single virus; and those infected with two or three viruses.

Samples collected in the second year of the study were submitted to real-time PCR for RSV, HRV, and HMPV. Total RNA was extracted by the TRIzol method (Life Technologies, Carlsbad, CA, USA) according to the manufacturer's instructions. cDNA was synthesized with a Superscript III kit (Invitrogen, Karlsruhe, Germany) and quantified with the Qubit assay (DNA HS; Invitrogen). The quality of the cDNA for each patient was tested by amplification of the endogenous $\beta$-actin gene with a real-time PCR system (StepOne ${ }^{\mathrm{TM}}$; Applied Biosystems,
Foster City, CA, USA), including TaqMan Master Mix (Applied Biosystems) and specific primers (Applied Biosystems). Samples that did not amplify $\beta$-actin were excluded from the analysis. Quantitative real-time PCR reactions were performed to amplify HRV-, RSV-, HMPV-specific genes using 4 ng of cDNA in triplicate for each patient. Primer sequences, synthesized and cloned into pUC57 plasmids (GenScript, Piscataway, NJ, USA), were used in order to perform a 10 -fold dilution and generate a standard curve starting at $4 \mathrm{ng}$. This test was performed in all patients during the second year of the study (September 2010 to August 2011) and was used in order to investigate the effect that viral load has on the markers of bronchiolitis severity.

The viral load (in copies $/ \mathrm{mL}$ ) was calculated from the amount of cDNA used in the PCR. Statistical analysis of the viral load was performed using GraphPad Prism, version 5.02 (Graphpad Software, San Diego, CA, USA).

The study was approved by the Research Ethics Committee of the Pontifical Catholic University of Rio Grande do Sul (Protocol no. 09/04 678). The parents or legal guardians of all participants gave written informed consent.

Data were summarized as mean \pm standard deviation or as or median and interquartile range, depending on their distribution. Characteristics were compared between the two groups. The variables presented nonparametric distribution. The nonparametric Kruskal-Wallis test was used in order to compare continuous variables between the groups. To correlate continuous variables (e.g., viral load and length of hospitalization), we used Pearson's or Spearman's correlation tests. The level of statistical significance was set at $p \leq 0.05$. Data analysis was performed with the Statistical Package for the Social Sciences, version 17.0 (SPSS Inc., Chicago, IL, USA).

\section{RESULTS}

Between September of 2009 and August of 2011, we recruited 127 patients, 110 of whom met all of inclusion criteria (first wheezing episode). Clinical information was collected for all of the patients included. In all 110 patients, the nasal samples collected were adequate for analysis by DIF, and 56 samples were submitted to quantitative real-time PCR in order to identify specific respiratory viruses (HRV, RSV, and HMPV). The mean age of the patients was 3.21 months, and 62 (56.3\%) of the 110 patients were male (Table 1 ). Of the 110 infants evaluated, 109 (99.1\%) had subcostal or intercostal retractions and required oxygen therapy. The mean hospital stay was 6 days, and none of these infants were admitted to the intensive care unit or needed mechanical ventilation (Table 1 ).

Of the 110 samples analyzed by DIF, 72 (65.4\%) tested positive for a virus and $38(34.6 \%)$ tested negative. The most common virus was RSV, which was identified in $65(90.2 \%)$ of the 72 positive samples, followed by influenza, identified in 15 (20.8\%); parainfluenza, identified in $10(13.8 \%)$; and adenovirus, identified in $3(4.1 \%)$. In the sample as a whole, 56 (50.9\%) of the 110 patients tested positive for one virus and $16(14.5 \%)$ tested positive for two or three viruses. Coinfection was not found to influence the 
length of the hospital stay or any other variable (Table 2 ). Among the 56 samples analyzed with quantitative real-time PCR (during the second year of the study), specifically to evaluate the impact of viral load, RSV was again the virus most often detected, being identified in $19(76 \%)$ of the 25 positive samples, followed by HRV, which was identified in $4(16 \%)$, and HMPV, which was identified in $2(8 \%)$. The quantitative real-time PCR analysis showed that, in the second year of the study, $31(55.3 \%)$ of the 56 patients tested negative, $24(42.8 \%)$ tested positive for one virus, and $1(1.7 \%)$ tested positive for two viruses.

The mean viral loads for RSV, HRV, and HMPV were $1,340,000$ copies $/ \mathrm{mL}, 614,000$ copies $/ \mathrm{mL}$, and 175,000 copies/mL, respectively. As can be seen in Figure 1, the RSV viral load in the nasal secretions, as determined by real-time PCR, showed no significant correlation with markers of clinical severity in our study sample ( $p>0.05$ ). We found that viral loads did not influence the length of hospitalization or the duration of wheezing episodes.

\section{DISCUSSION}

In our study, RSV viral loads in infants with wheezing did not influence the length of the hospital stay, which was used as a marker of the severity of acute bronchiolitis or wheezing episodes. Given the role of viral infections in wheezing, the hypothesis that higher viral loads or coinfection with different types of viruses could influence the natural history of acute wheezing is reasonable and logical. ${ }^{(7)}$ However, the association between viral loads and severity remains unclear and controversial in the literature, as does that between coinfection and severity. ${ }^{(8-11)}$ In clinical practice, the size of the viral load and infection with more than one virus may generate uncertainty about the prognosis of such infections. ${ }^{(4)}$ In the present study, the severity of acute wheezing was not affected by the RSV viral loads in nasopharyngeal secretions.

When we used DIF in order to diagnose infection with respiratory viruses (influenza, parainfluenza, adenovirus, or RSV), we found that approximately $65 \%$ of the samples were positive for at least one such pathogen. Our DIF results are similar to those obtained in previous studies in the literature, in which the reported rate of infection with respiratory viruses among children with respiratory symptoms ranges from $45 \%$ to $70 \%$. $^{(12)}$ In the present study, RSV was the most prevalent pathogen, whether alone or together with another virus.

Real-time PCR was positive for RSV, HRV, and HMPV in $44.6 \%$ of the analyzed samples. That rate of positivity is in contrast with the $93.5 \%$ reported in a study that used conventional and real-time PCR for 12 different respiratory viruses. ${ }^{(13)}$ However, it is similar to the rates reported in studies using only real-time PCR, which ranged from $44 \%$ to $64 \%$. $^{(14,15)}$ Our study was underpowered to analyze the impact of coinfection on disease severity. Currently, the reported effects of

Table 1. Characteristics of patients according to the questionnaire completed at admission and variables associated with clinical severity. ${ }^{\text {a }}$

\begin{tabular}{lc}
\multicolumn{1}{c}{ Characteristic } & $\begin{array}{c}\text { Acute bronchiolitis (first wheezing episode) } \\
\text { (N }=110 \text { ) }\end{array}$ \\
Age, months & $3.21 \pm 2.5$ \\
Male gender, $\mathrm{n}(\%)$ & $62(56.3)$ \\
Current weight, $\mathrm{kg}$ & $5.66 \pm 1.90$ \\
Siblings, $\mathrm{n}(\%)$ & $67(60.9)$ \\
Length of hospital stay, days & $6.05 \pm 3.22$ \\
Respiratory rate, breaths/min & $50.58 \pm 11.60$ \\
SpO on admission, \% & $95.27 \pm 3.42$ \\
Retractions, $\mathrm{n}(\%)$ & $109(99.1)$ \\
Mechanical ventilation, $\mathrm{n}(\%)$ & $0(0.0)$ \\
Use of oral steroids, $\mathrm{n}(\%)$ & $8(7.3)$ \\
\hline
\end{tabular}

aResults presented as mean \pm standard deviation, except where otherwise indicated.

Table 2. Severity associated with the number of respiratory viruses identified by direct immunofluorescence. ${ }^{\mathrm{a}}$

\begin{tabular}{lccc}
\multicolumn{1}{c}{ Variable } & Number of viruses identified & * $^{*}$ \\
& $\mathbf{1}$ & $\mathbf{2 - 3}$ & \\
Age, months & $(\mathbf{n}=\mathbf{5 6})$ & $\mathbf{( n = 1 6 )}$ & 0.373 \\
Current weight, $\mathrm{kg}$ & $3.00 \pm 2.47$ & $2.38 \pm 2.42$ & 0.974 \\
Respiratory rate, breaths/min & $5.51 \pm 1.88$ & $5.50 \pm 1.90$ & 0.557 \\
$\mathrm{SpO}_{2}$ on admission, \% & $51.09 \pm 12.51$ & $49.06 \pm 10.53$ & 0.601 \\
Days on oxygen therapy & $95.14 \pm 3.46$ & $94.63 \pm 3.52$ & 0.377 \\
Length of hospital stay, days & $6.17 \pm 2.93$ & $5.44 \pm 2.96$ & 0.188 \\
Duration of wheezing, days & $6.83 \pm 3.22$ & $5.63 \pm 3.22$ & 0.402 \\
\hline
\end{tabular}

aResults presented as mean \pm standard deviation. *Comparisons by Student's t-test. 
(A)

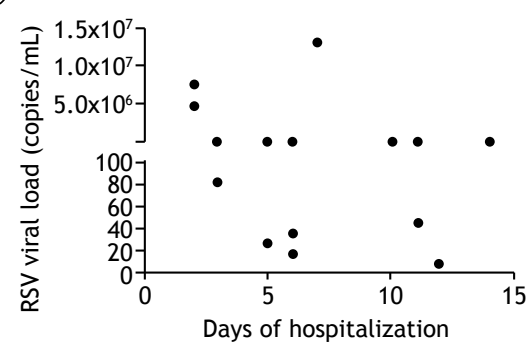

(C)

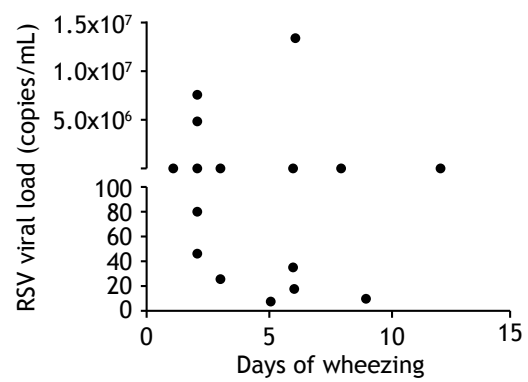

(B)

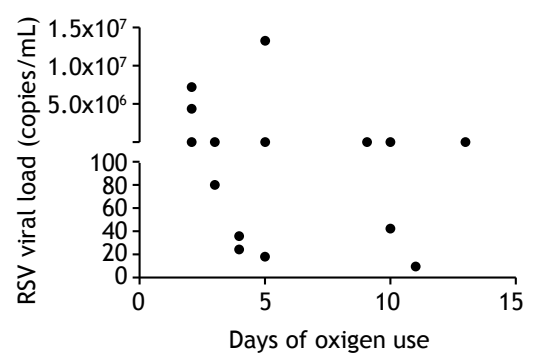

Figure 1. Respiratory syncytial virus (RSV) viral load, in correlation with days of hospitalization (A*), days of oxygen use (B), and days of wheezing (C). ${ }^{*} r=-0.217 ; p=0.372$.

coinfection on the burden of disease among children are inconsistent and controversial. One possible explanation is that such effects occur only in specific circumstances, such as RSV/HRV coinfection ${ }^{(5)}$ or RSV/ HMPV coinfection. In addition, several environmental factors can also be determinants of the severity of respiratory viral infections, as can genetic variations in genes linked to the immune response against infections. (13-15)

In the present study, we believe that the lack of an association between viral load and outcome measures of severity stands out as the main result. In such analysis, one could have expected a correlation or a trend in the plot between the variables viral load and length of hospitalization. However, there was absolutely no trend or correlation between the two. Previous studies on viral load and severity have also reported conflicting findings. Few studies have investigated the association between disease severity and viral load. Fodha et al. ${ }^{(10)}$ described a positive correlation between RSV viral load and disease severity (determined by respiratory rate, length of hospital stay, and need for admission to the intensive care unit) in children hospitalized with respiratory infection. Zhou et al. ${ }^{(16)}$ and Hasegawa et al. ${ }^{(17)}$ showed that a higher mean RSV viral load was associated with greater disease severity, as well as with a longer duration of hospitalization and symptoms.
Nevertheless, there have also been reports of negative and inverse associations. Martin et al. ${ }^{(11)}$ reported that an increasing viral load in RSV-infected children was associated with decreases in inpatient admissions, antibiotic use, and respiratory rates. In comparison with our patient sample, the sample evaluated by those authors was considerably larger, comprising 1,264 infants, 418 of whom tested positive for RSV by quantitative PCR. The authors detected borderline inverse associations (e.g., OR $=0.80 ; 95 \% \mathrm{Cl}$ : 0.70-0.99 for hospital admission). Considering these findings, we have to raise the possibility of random associations or lack of an association between viral load and disease severity in acute wheezing episodes.

Our study has some relevant limitations, such as the small sample size, single nasal sample collection, and the use of PCR tests only in a subsample. However, our findings add to the current knowledge by suggesting that there is no correlation between viral load and the severity of respiratory illness in infants.

In conclusion, on the basis of our results, neither coinfection nor viral load appears to influence the major outcomes of acute bronchiolitis. We also found that RSV viral loads in infants with wheezing did not influence the severity of the acute wheezing episodes in the first year of life. Further studies investigating the effects of viral load and viral combinations may help clarify this important and controversial issue.

\section{REFERENCES}

1. Sole D. Childhood wheezing [Article in Portuguese]. J Bras Pneumol. 2008;34(6):337-9. PMID: 18622498

2. Kotaniemi JT, Pallasaho $P$, Sovijärvi $A R$, Laitinen LA, Lundbäck $B$. Respiratory symptoms and asthma in relation to cold climate, inhaled allergens, and irritants: a comparison between northern and southern Finland. J Asthma. 2002;39(7):649-58. http://dx.doi.org/10.1081/JAS120014930

3. Lima JA, Fischer GB, Sarria EE, Mattiello R, Sole D. Prevalence of and risk factors for wheezing in the first year of life. J Bras Pneumol. 2010;36(5):525-31. PMID: 21085816

4. De Paulis M, Gilio AE, Ferraro AA, Ferronato AE, do Sacramento $\mathrm{PR}$, Botosso VF, et al. Severity of viral coinfection in hospitalized infants with respiratory syncytial virus infection. J Pediatr (Rio J). 2011;87(4):307-13. http://dx.doi.org/10.2223/JPED.2100

5. da Silva ER, Pitrez MC, Arruda E, Mattiello R, Sarria EE, de Paula FE, et al. Severe lower respiratory tract infection in infants and toddlers 
from a non-affluent population: viral etiology and co-detection as risk factors. BMC Infect Dis. 2013;13:41. http://dx.doi.org/10.1186/14712334-13-41

6. Miron D, Srugo I, Kra-Oz Z, Keness Y, Wolf D, Amirav I, et al. Sole pathogen in acute bronchiolitis: is there a role for other organisms apart from respiratory syncytial virus? Pediatr Infect Dis J. 2010;29(1):e7e10. http://dx.doi.org/10.1097//NF.0b013e3181c2a212

7. Richard N, Komurian-Pradel F, Javouhey E, Perret M, Rajoharison A, Bagnaud $A$, et al. The impact of dual viral infection in infants admitted to a pediatric intensive care unit associated with severe bronchiolitis. Pediatr Infect Dis J. 2008;27(3):213-7. http://dx.doi.org/10.1097/ INF.0b013e31815b4935

8. Stempel HE, Martin ET, Kuypers J, Englund JA, Zerr DM. Multiple viral respiratory pathogens in children with bronchiolitis. Acta

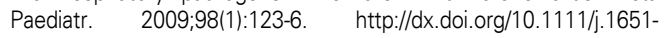
2227.2008.01023.x

9. Franz A, Adams O, Willems R, Bonzel L, Neuhausen N, SchweizerKrantz S, et al. Correlation of viral load of respiratory pathogens and co-infections with disease severity in children hospitalized for lower respiratory tract infection. J Clin Virol. 2010;48(4):239-45. http:// dx.doi.org/10.1016/j.jcv.2010.05.007

10. Fodha I, Vabret A, Ghedira L, Seboui H, Chouchane S, Dewar J, et al. Respiratory syncytial virus infections in hospitalized infants: association between viral load, virus subgroup, and disease severity. J Med Virol. 2007;79(12):1951-8. http://dx.doi.org/10.1002/jmv.21026

11. Martin ET, Kuypers J, Heugel J, Englund JA. Clinical disease and viral load in children infected with respiratory syncytial virus or human metapneumovirus. Diagn Microbiol Infect Dis. 2008;62(4):382-8. http://dx.doi.org/10.1016/j.diagmicrobio.2008.08.002
12. Calegari T, Queiroz DA, Yokosawa J, Silveira HL, Costa LF, Oliveira TF, et al. Clinical-epidemiological evaluation of respiratory syncytial virus infection in children attended in a public hospital in midwestern Brazil. Braz J Infect Dis. 2005;9(2):156-61. http://dx.doi.org/10.1590/ S1413-86702005000200006

13. Martin ET, Kuypers J, Wald A, Englund JA. Multiple versus single virus respiratory infections: viral load and clinical disease severity in hospitalized children. Influenza Other Respir Viruses. 2012;6(1):71-7. http://dx.doi.org/10.1111/j.1750-2659.2011.00265.x

14. Canducci F, Debiaggi M, Sampaolo M, Marinozzi MC, Berrè S, Terulla $\mathrm{C}$, et al. Two-year prospective study of single infections and coinfections by respiratory syncytial virus and viruses identified recently in infants with acute respiratory disease. J Med Virol. 2008;80(4):71623. http://dx.doi.org/10.1002/jmv.21108

15. Jennings LC, Anderson TP, Werno AM, Beynon KA, Murdoch DR. Viral etiology of acute respiratory tract infections in children presenting to hospital: role of polymerase chain reaction and demonstration of multiple infections. Pediatr Infect Dis J. 2004;23(11):1003-7. http:// dx.doi.org/10.1097/01.inf.0000143648.04673.6c

16. Zhou L, Xiao Q, Zhao Y, Huang A, Ren L, Liu E. The impact of viral dynamics on the clinical severity of infants with respiratory syncytial virus bronchiolitis. J Med Virol. 2015;87(8):1276-84. http://dx.doi. org/10.1002/jmv.24111

17. Hasegawa K, Jartti T, Mansbach JM, Laham FR, Jewell AM, Espinola $\mathrm{JA}$, et al. Respiratory syncytial virus genomic load and disease severity among children hospitalized with bronchiolitis: multicenter cohort studies in the United States and Finland. J Infect Dis. 2015;211(10):1550-9. http://dx.doi.org/10.1093/infdis/jiu658 